\title{
DIGITAL TECHNOLOGIES FOR COGNITIVE LINGUISTICS STUDIES IN MAGISTRACY
}

\author{
Inna Petrova \\ Moscow City University, Russian Federation
}

\begin{abstract}
The field of higher education in Russia is undergoing significant changes that require reviewing past practices and professional activities. This article aims to study the potential of using modern digital technologies in linguistic experiments in cognitive linguistics regarding writing master's degree theses.

The analysis of recent cognitive studies has shown that the area for this research is diverse and includes investigating aspects of cognitive semantics, translation techniques, concordance, phrase variability, and others. Research results show that cognitive science widely uses empirical data received through digital technologies such as Google. This digital tool can be accessible and suitable for linguistic experiments and the author demonstrates its application. The paper presents a model of the linguistic experiment on studying the variability of the structure of a conceptual binominal phrase in Russian and English. According to the obtained results, Russian users of the Internet feature a higher tendency for changing the order the binomial concepts than the English-speaking ones. These data provide language material for conclusions and further considerations from a cognitive perspective. The framework of this experiment can be a motivating factor for those who want to master their research and language skills in the magistracy.
\end{abstract}

Keywords: big data, cognitive linguistics research, corpus-driven studies, digitization, higher education, linguistic experiment, master's degree.

\section{Introduction}

Master's degree not only allows graduates to gain a high level of professionalism, the ability to solve complex management, analytical, research tasks, but it also is a link to Life Long Learning (LLL). LLL is becoming more meaningful and important nowadays, and the higher education sector is progressively increasing its provision of lifelong learning worldwide. Master's degree programs offer a great opportunity for LLL. Many studies devoted to the problems of training in magistracy acknowledge the importance of this stage in the teacher's education (Katashinskih, 2012; Fattakhova, Yusupova, \& Fedorova, 2016; Hamidullina, 2017; Kvashina, 2017). An essential factor of training in the master's degree is the research activity of students. "Research is important because it helps us to understand the society and framework we live in and because it gives us the means to make life better" (Erixon, Frånberg, \& Kallós, 
2001, p.9). In addition, research in linguistics afford undergraduates to get up-todate knowledge, learn about new achievements and employ new digital technologies for expanding the personal experience in the language studies. "It is important to create possibilities for learners to explore and discover on their own so that ideas and knowledge come from real solutions related to learners' personal experience” (Bubnys, 2019, p.90).

Although many studies have indicated that research is highly important for the development of a language teacher, there is an insufficient number of papers devoted to particular research tools applicable to use in the context of such research. Our investigation in this area revealed that there are some digital resources suitable for language studies from a cognitive perspective at the analyzed level of education. In this paper, we establish perspective research areas for the students studying on master's programs on language and cognitive linguistics and indicate available modern digital tools for such research. As a result, this paper presents a model of a linguistic experiment utilizing a digital research tool for the cognitive study of the word order of conceptual binominals in different languages.

The research aim is to analyze trends of prospective usage of cognitive corpus linguistics in educating master's degree students. The present investigation involves observation of literature on corpus cognitive linguistics and on usage of Google search in these studies. This analysis helps to find potential areas of research for master's dissertations in cognitive corpus linguistics. The experimental approach enables to propose a model of a linguistic experiment in the framework of discovered areas that is designed to obtain data for further cognitive studies. In our model experiment, we test variability of conceptual binominals in Russian and English using data from Google as corpus analogue. To establish in which language the variability is more frequent, we compare the obtained data and calculate the percentage ratio of conceptual binomial word order variability in Russian and English. The result shows what language has more tendency for changing word order in the binominals. Further studies of these data may be of considerable practical value in language research on the master's level.

\section{Literature review}

Recent studies reveal a strong link between language studies, linguistics and cognitive linguistics. This is because cognitive linguistics plays a leading role in modern linguistic research. A great number of cognitive linguist associations such as the International Cognitive Linguistics Association (ICLA), the Russian Cognitive Linguists Association (RCLA), the Polish Cognitive Linguistics Association (PCLA) and many studies prove this statement. The vast researchers' interest results in numerous master's degree programs in cognitive linguistics 
offered by different universities, for example, universities of Russia, Germany, the USA and other countries.

Studying cognitive phenomena through the prism of linguistics is the core of cognitive linguistics. Cognitive linguistics offers new perspectives in traditional language problems; it puts forward new insights and explanations for most challenging long-standing issues. It is believed that the shift from the objectivist view of cognition and language to the empirical view of cognition and language marks the progress of human knowledge and the study of language philosophy (Dapeng, 2014).

There are many promising research areas in cognitive linguistics, for example, the study of speech and mental mechanisms, cognitive studies of text and discourse and others. The motivation for this literature review stems from several existing studies dealing with the cognitive and language phenomena we consider relevant in the context of the master's programs. In our view, they provide a wide range of ideas for further studies.

First, along with the mentioned above areas, we regard such application of theoretical knowledge as the evolution of language and cognition by integrating evolutionary linguistics and the framework of cognitive linguistics (Pleyer \& Winters, 2014).

Second, there is the convergence of cognitive linguistic research and sociallinguistic research. Cognitive sociolinguistics creates new values within cognitive linguistics for both linguistic study and social study, opens up new horizons for cognitive linguistics, and in the meantime, it is a continuation of the 20th-century revolution against Chomskian generative linguistics (Chevrot, Drager, \& Foulkes, 2018).

Third, the study of syntax, the syntax of dialogue, in particular, can have a big potential for further research. The mechanism of utter construction in dialogues: dialogic syntax has such key theoretical features as the dialogical syntax, real abstractions, application of dialogic bootstrapping strategy, and dialogic analysis of spoken language constructions. The study of this phenomenon broadens cognitive studies of syntax, thus representing a new research trend in cognitive linguistics (Guocai, 2015).

Thus, we have established several areas in modern cognitive studies having great potential for further development both on master's programs on linguistics and cognitive linguistics in particular.

In order to identify the applicable research tool, this paper analyzes several recent studies on this matter. The era of the Internet provided people with a vast opportunity of getting information of various kinds to investigate and analyze it from different perspectives. University staff widely use digital and interactive technologies (Sorokovyh, Kappusheva, Gerasimova, Olejnikova, Korotkova, Baranova, \& Nadzhafov, 2013). 
Corpus techniques in language studies have become a common practice in higher education establishments (Conroy, 2010; Blanchard, Tetreault, Higgins, Cahill, \& Chodorow, 2013 and others).

Corpus techniques and cognitive approaches have widespread adoption in the practice of teaching a foreign language, for example, in the study of phrasal verbs. They may present difficulty because of their number and polysemy. Teaching phrasal verbs through cognitive linguistics by combining the theory of event conflation with corpus-based research allows creating a list of phrasal verb particles and meanings. For example, R. Spring showed in his research that this method provides evidence that learners taught with the particle list improved their ability to conjecture the meanings of novel phrasal verbs more effectively than learners who studied common phrasal verbs as whole units (Spring, 2018).

Some papers apply corpus-based cognitive semantics to translation studies (TS) who are particularly interested in revealing evaluative aspects of the units of meaning of source texts and their translations. As K. Zethsen puts it, what may formerly be described as something intangible like an 'atmosphere', now becomes tangible because of the patterns emerging from large numbers of examples. Empirical examples in various languages of such evaluative patterns are not automatically generated but come about as the result of computer-generated concordance lines and thorough manual analysis (Zethsen, 2008).

Moreover, modern corpus linguistics has crossed the line that limits researchers only to a certain structured corpus of given texts. Internet search engines have opened up new opportunities for scientists studying different aspects of language and speech. In particular, the use of search engines such as Google or Yandex allows receiving significant empirical material, which can serve as a source of study of various linguistic phenomena associated with cognitive processes (Suleymanova, 2019; Petrova, 2019).

The relative ease and accessibility of gaining such databases can be an attractive factor for young researchers studying for master's programs in the cognitive direction. These tools allow, for example, studying concordance of different elements of language. Until recently, it was assumed that to study concordance we require specialized software, but it turns out that a search engine such as Google can generate queries into almost limitless corpora, for example, using the Advanced Search feature from the main portal page (Robb, 2003; Sha, 2010).

This affords the implementation of data-driven learning (DDL), or corpusbased language learning, which involves the learner in an exploratory task to discover appropriate expressions or collocates regarding his writing. However, the problematic units of meaning in each learner's writing are so diverse that conventional corpora often prove futile. The search engine Google with the characteristics of dynamic corpora can provide quantitative parameters for 
evaluating a chunk of language. Thus, we consider that employing Google as a research tool will enable a prospective master's degree researcher to widen the range of potential investigation areas within cognitive linguistics. A linguistic experiment presented in this paper can serve as an example of such a study.

\section{Materials and methods}

The proposed experiment deals with the structural variability of a phrase. Structural variability studies involve issues of cognitive modeling of syntax. This is due to the principles that organize the speech-making activity of a person. There is the principle of specification (or the principle of individualization), which implies an individual understanding of the event with the allocation of its details (Furs, 2007, p.82). Thus, by using different structural variants of the phrase, the speaker realizes the principle of individualization in his speech-making activity.

In the model experiment, we consider the structure of conceptual binominals, which include two nouns with conjunction and, for example, добро $и$ зло - good and evil. These nouns possess conceptual meaning in Russian and English. The order of components in the binominals reveals the importance of each element: the most important element goes first. The change in the order of components exposes a shift in the cognitive focus of the speaker. The comparison of structural variability of binominals in the two languages can shed some light on the process of conceptualization in both languages.

The experiment aims to investigate Google's potential for cognitive research to provide empirical data for the study of the variability of phrases in different languages.

The material of the experiment is a conceptual binominal phrase in Russian and English: (1) добро и зло/ good and evil and (2) жизнь и сметь/ life and death.

The task is to compare the frequency of variability of word order of these conceptual binominal phrases in two languages. To fulfill the task, we used an advanced search with the exact phrase and rich text format. Table 1 shows the results of the empirical data.

Table 1 Number of entries of conceptual binomial (Retrieved from Google 2.12.2019)

\begin{tabular}{|l|c|l|}
\hline \multicolumn{1}{|c|}{ Phrase } & Russian & English \\
\hline 1.1. добро и зло/ good and evil & 1,930 & 12,800 \\
\hline 1.2. зло и добро / evil and good & 172 & 943 \\
\hline 2.1. жизнь и сметь/life and death & 1,870 & 38,400 \\
\hline 2.2. смерть и жизнь/ death and life & 979 & 5,650 \\
\hline
\end{tabular}


The data show that there is the variability of the word order in the conceptual binomial pair. Thus, Google has provided empirical data for the further analyses from a cognitive perspective.

\section{Research results}

The analysis of the percentage of phrases 1.1.; 1.2. and 2.1.; 2.2. will show in which of the languages the variability of the word order of a conceptual binominal phrase is higher. I calculated the percentage using Formula 1:

Percentage $=($ Value $/$ Total Value $) \times 100$

Where Total value is the number of entries of phrases, 1.1. and 2.1.,

Value is the number of entries of phrases 1.2. and 2.2.

Table 2 presents the result of the calculations.

Table 2 Percentage ratio of conceptual binomial word order variability in Russian and English

\begin{tabular}{|l|c|c|}
\hline \multicolumn{1}{|c|}{ Variability of the word order of the phrases } & Russian & English \\
\hline $\begin{array}{l}\text { 1.1.-1.2. } \\
\text { добро и зло/ зло и добро } \\
\text { good and evil/ evil and good }\end{array}$ & $8,9 \%$ & $7,3 \%$ \\
\hline $\begin{array}{l}\text { 2.1.-2.2. } \\
\text { жизнь и смерть/ смерть и жизнь } \\
\text { life and death/death and life }\end{array}$ & $52,4 \%$ & $14.7 \%$ \\
\hline
\end{tabular}

These results show that Russian users of the Internet feature a higher tendency for changing the order the binomial concepts than the English-speaking ones. These results provide material for conclusions and further studies in the language environment of these data. Analyzes of the vast textual data will elucidate details of the established linguistic fact, which is not the subject of this paper. Thus, the experiment proves the potential of the Google search to provide statistical data relevant to cognitive studies. Though this approach does not replace other methods of linguistic research, it can enrich our understanding of cognitive and linguistic phenomena.

\section{Conclusions}

Modern linguistic education allows students to realize the concept of LLL and their research potential in the framework of master's programs in cognitive linguistics. Knowledge in cognitive linguistics can be helpful not only in teaching languages but in investigating issues of artificial intelligence, cultural and social 
phenomena and others. There are some areas in cognitive linguistics that can have great potential for further studies at master's level, such as the study of syntax variability, conceptualization and categorization of the meaning and social and cultural aspects of the language. Research in cognitive science actively exploits empirical data obtained through digital technologies, in particular by the Internet search such as Google. This digital tool due to its accessibility and adjusting coverage widens the scope of linguistic experiments that opens up broad prospects for young researchers in this field. Our observation suggests the possibility that a various number of languages can be the subject of investigation and comparison from the cognitive perspective using this digital tool. However, some limitations should be noted. First, Google as a tool can be suitable for gathering empirical data, which have parameters strictly identified by the purpose of the research. Second, a sophisticated method of the analysis of such data is necessary. This paper provides a preliminary approach for the research of this kind. The application of this technology in cognitive linguistics demands further research.

\section{References}

Blanchard, D., Tetreault, J., Higgins, D., Cahill, A., \& Chodorow, M. (2013). TOEFL11: A corpus of non-native English. ETS Research Report Series, 2013(2), 1-15.

Bubnys, R. (2019). Future educators' learning trends at the university: how important and significant the learner's experience is? Society, integration, education: Proceedings of the International Scientific Conference, 1, 89-98. DOI: http://dx.doi.org/10.17770/ sie2019vol1.3855

Conroy, M.A. (2010). Internet tools for language learning: University students taking control of their writing. Australasian Journal of educational technology, 26(6), 861-882.

Chevrot, J.-P., Drager, K., \& Foulkes, P. (2018). Editors' Introduction and Review: Sociolinguistic Variation and Cognitive Science. Topics in cognitive science, 10(4), 679-695.

Dapeng, W. (2014). The Role of Cognitive Linguistics in Promoting Language Research. 2014 Conference on Informatisation in Education, Management and Business (IEMB-14), 364-366.

Erixon, P.-O., Frånberg, G.-M., \& Kallós, D. (2001). The role of graduate and postgraduate studies and research in teacher education reform policies in the European Union. Umeå: Umeå Universitet.

Fattakhova, N.N., Yusupova, Z.F., \& Fedorova, N.I. (2016). A New Model of Pedagogical Magistracy in the Direction of "Linguistic Education" at Kazan Federal University. The European Proceedings of Social \& Behavioural Sciences EpSBS: IFTE 2, 26-29.

Furs, L.A. (2007). Cognitive modeling of syntax, Issues of cognitive linguistics, 4, 81-85.

Guocai, Z. (2015). Dialogic syntax: A new research trend in cognitive linguistics. Modern Foreign Languages, 38(6), 842-848.

Hamidullina, L.A. (2017). On continuous professional development of modern specialists. Priority directions of development of education and science: Proceedings of the III International scientific and practical conference, 191-193. 
Katashinskih, V.S. (2012). Sociological analysis of the students' orientation concerning graduate school studies, Izvestia Ural Federal university journal. Series 1: Issues in education, science and culture, 4(107), 135-139.

Kvashina, S.Y. (2017). Master's degree as a requirement for the professional growth of teachers. Actual problems of social and humanitarian sciences: a collection of scientific works on the materials of the International scientific and practical conference, 48-50.

Petrova, I.M. (2019). The potential of Google search for studies in cognitive corpus linguistics, Theoretical and applied linguistics, 5(3), 127-142.

Pleyer, M., \& Winters, J. (2014). Integrating cognitive linguistics and language evolution research. Theoria et Historia Scientiarum, 11, 19-44.

Robb, T. (2003). Google as a quick and dirty corpus tool. TESL-EJ, 7(2). Retrieved from http://www.tesl-ej.org/ej26/int.html

Suleimanova, O.A. (2019). Semantic experiment: new approaches via Big-data, Cognitive Studies of Language, 36, 427-432.

Sha, G. (2010). Using Google as a super corpus to drive written language learning: a comparison with the British National Corpus. Computer Assisted Language Learning, 23(5), 377-393.

Sorokovyh, G.V., Kappusheva, H.H., Gerasimova, N.I., Olejnikova, E.A., Korotkova, I.P., Baranova, E.A., \& Nadzhafov, I.A. (2013). Interactive technologies in foreign language education: research of strategies and experience of the application. Moscow: OOO Perspectiva.

Spring, R. (2018). Teaching phrasal verbs more efficiently: using corpus studies and cognitive linguistics to create a particle list. Advances in Language and Literary Studies, 9(5), 121-135.

Zethsen, K.K. (2008). Corpus-based cognitive semantics: Extended units of meaning and their implications for Translation Studies. Linguistica Antverpiensia, New Series-Themes in Translation Studies, 7, 249-262. 